\title{
Epochale Momente
}

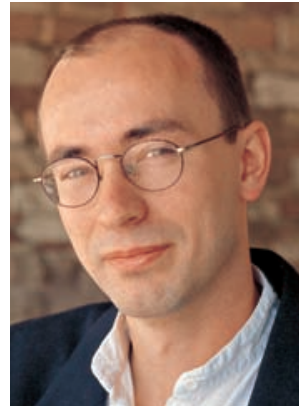

Dr. med. Dieter Schmid, Redaktionsleitung
Im Leben jedes jungen Mediziners gibt es denkwürdige Momente, die er nie vergessen wird. Einer ist sicher, wenn er zum ersten Mal eine Wunde zunähen darf. Bei mir spielte sich dieses feierliche Ereignis so ab: Ich war Chirurgie-PJler und stand seit gefühlten sechs Stunden am OP-Tisch. Plötzlich sprach der Oberarzt den entscheidenden Satz: „Na, willste mal zunähen?“ Vor Schreck fielen mir fast die Haken aus den Händen, und das in den Beinen versackte Blut schoss mir binnen Sekunden hoch in den Kopf. Als mir die OP-Schwester dann den Nadelhalter reichte, konnte ich das Instrument vor Aufregung kaum halten. Zwar gelang es mir wider Erwarten, die Wunde ganz manierlich zu verschließen, und soweit ich mich erinnere, ist sie danach auch wirklich verheilt - aber angenehm war die ganze Prozedur nicht. Weder für den netten 1. Assistenten, der mir mit einer Engelsgeduld half und die ihm vom Oberarzt eingebrockte Suppe auslöffeln durfte, noch für mich selbst, denn ich war auf diese Situation einfach mies vorbereitet. Damit es Ihnen besser ergeht, lesen Sie unseren Artikel „Nähstunde für Weißkittel“ auf S. 34! Hier haben wir die Grundlagen des „Nähens \& Knüpfens“ praxisnah für Sie aufbereitet.

Die epochalsten Ereignisse im Studium sind aber natürlich die Ärztlichen Prüfungen. Ihrem Rang angemessen legen sich die Studierenden in den Vorbereitungsphasen darauf besonders ins Zeug. Dass es manche dabei übertreiben, zeigt das Ergebnis einer Online-Umfrage, die wir kürzlich durchgeführt haben: $36 \%$ der Teilnehmer gaben an, dass sie in der heißen Lernphase vor einem Examen über 10 Stunden pro Tag lernen - und das, obwohl Lernexperten klar sagen, dass mehr als 7 Stunden nichts bringen. 30\% der Medizinstudenten stellen ihre Freizeitaktivitäten in den zwei Monaten vor der Prüfung praktisch vollständig ein. 15\% konsumieren Medikamente zur Leistungssteigerung oder Angstlösung. Kein Wunder, dass sich viele Prüflinge nach dem Examen fühlen, als seien sie gerade aus einer Gruft geklettert - sofern sie dazu noch in der Lage sind. Unsere Autorin Nele Camerer hat im Gespräch mit Psychologen und Ernährungsexperten einen guten Plan entwickelt, wie man in Prüfungsphasen trotz der großen Lernbelastung gesund bleiben kann. Ihre Tipps finden Sie im Artikel „Finde deinen Rhythmus!“ auf S. 12.

Ein Tipp für höhere Semester: Mit Erscheinen dieses Heftes startet unsere PJ-Umfrage 2011, die wir dieses Mal in Kooperation mit der bvmd durchführen. Möchten Sie dazu beitragen, dass sich die Qualität dieser wichtigsten Ausbildungsphase im Studium endlich so darstellt, wie es sich gehört? Dann machen Sie mit! Infos auf S. 27 oder unter www.thieme.de/viamedici/medizinstudium/pj/umfrage11.html.

Einen Epoche machenden Sommer wünscht Ihnen

Ihr

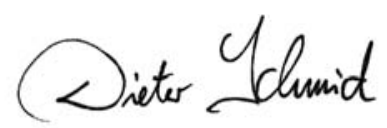

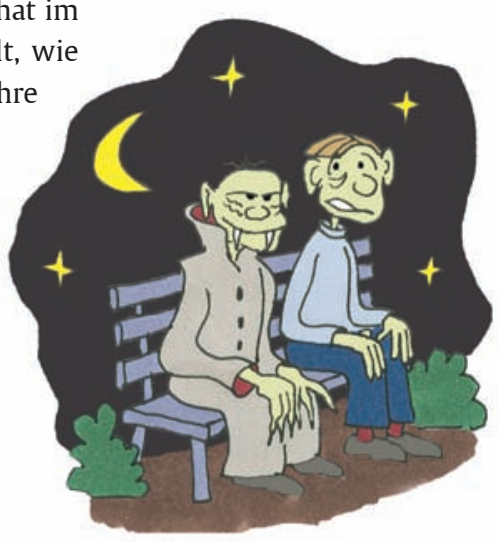

„Na, haste auch Physikum nächste Woche?“

\section{ONLINE-UMFRAGE}

\section{Plagiate in Doktorarbeiten: Welche Strafe ist angemessen?}

Was unter Schülern weit verbreitet ist, kann im späteren Leben die Karriere kosten: abschreiben. In einer Doktorarbeit müssen daher alle Fremdpassagen entsprechend gekennzeichnet sein. KarlTheodor zu Guttenberg tat dies nicht und musste dafür seine Politikerkarriere an den Nagel hängen. Seither tauchen immer mehr Plagiatsvorwürfe gegen Prominente in der Presse auf. Ist Plagiarismus auch in der Medizin ein Problem? Wie würden Sie Fälle ahnden, in denen sich Jungmediziner den
„Dr. med.“ aus „fremden Federn“ zusammenschustern? Würden Sie Plagiatoren mit Berufsverbot belegen? Eine Geldstrafe verhängen? Oder halten Sie Plagiarismus für eine lässliche Sünde, bei der keine Sanktionen notwendig sind?

\section{- Welche Sanktionen halten Sie für} angemessen, wenn in einer Doktorarbeit ohne Quellenangabe abgeschrieben wird?

Stellen Sie sich dieser Frage und kommentieren Sie unter: www.thieme.de/viamedici/aktuelles/ aktion/miniumfrage3-11.html
- Ergebnis der Umfrage in Via medici 2.11: Wir fragten, ob die Bundesregierung einen anonymen Krankenschein für Migranten ohne Papiere einführen soll. 68\% waren dafür, nur 29\% dagegen, und 2\% hatten keine genaue Meinung zum anonymen Krankenschein. Einige waren der Ansicht, dass „alle Menschen das gleiche Recht auf medizinische Versorgung“ haben sollten. Die Gegenseite argumentierte, dass "Migranten nicht ins Sozialsystem einzahlen“ und „die Gelder im Gesundheitswesen eh schon knapp sind“. Mehr Kommentare unter: .../aktuelles/aktion/miniumfrage2-11.html 